\title{
Social Media, Misinformation and Covid-19
}

\author{
Bhavana Desai ${ }^{*}$, Samaya Pillai $^{2}$, Pramod Damle ${ }^{3}$ \\ ${ }^{1 *}$ Communication \& Information Section, Symbiosis International (Deemed University), Pune, India. \\ ${ }^{2,3}$ Symbiosis Institute of Digital and Telecom Management, Symbiosis International (Deemed University), Pune, \\ India. \\ 1*bsdesai70@gmail.com, ${ }^{2}$ samaya.pillai@sidtm.edu.in, ${ }^{3}$ pdamle@ sidtm.edu.in
}

Article History: Received: 10 November 2020; Revised: 12 January 2021; Accepted: 27 January 2021; Published online: 05 April 2021

\begin{abstract}
Social media has come as a boon, and as curse of spreading false news. Fake news has always been on the horizon even earlier. Only difference is that the fake news in earlier times was more risky and dangerous. Because in those times, identifying the fake news was not only difficult but propagating about it was also difficult. In these times, even though we have fake news the controlling measures are better and convincing people about them easy. With Covid-19, the pandemic in a century, people saw the havoc fake news can play. The paper defines, classifies Fake news. It discusses all the measures taken by various social media to address this issue. It also broadly gives an overview of the technical measures taken to address the issue.
\end{abstract}

Keywords: Social media, Fake news, misinformation, Facebook, Twitter, COVID-19, Coronavirus

\section{Introduction}

Man is a social animal. Gaining knowledge is an important aspect of humans. Human beings are inquisitive, and are dependent on different types of media to not only gain knowledge, but also to know about what's going on in the world. Newspapers came onto existence in the early 19th century. More and more newspapers came into existence and started venturing false stories to boost circulation. In 1835 the "Great Moon Hoax" published in the New York newspaper 'Sun' that there existed a civilization on the moon. This news established 'Sun' as one of the leading newspaper. Even before the social media came into existence the advent of the printing press has been a part of media.

With the advent of Internet, the mode of communication also changed drastically. In 1994, the first social networking site was created, and since then many more social networking sites are being created. Since the last decade, Internet has become an essential part of everyday life (Hamburger \& Vinitzk, 2010). According to (Nielsen 2011) Information transfer and social interaction are the most popular and fastest growing internet sites.

\subsection{What is social media?}

Social media can be defined as computer-mediated tools which enable people or organisations in creating, sharing and exchanging information, ideas, and pictures/videos virtually.

There are different types of Social networking sites like the following:

- Bookmarking Sites- These sites that allow users to save, organize and manage links to different websites all over the internet

- Social News -These that allow people to post news or links, and then users can "vote" on these news items.

- Media Sharing - For uploading and sharing pictures and videos.

- Microblogging - These sites allow to post short updates which can be pushed out to any person who has subscribed to these microblogging sites. Example - Twitter.

- Discussion forums - These are online forums or online discussion sites where people can converse by posting messages.

- E-Commerce - These sites are for transactions of online buying or selling.

- Blogs -These are used for virtual discussion of a particular topic of interest.

Facebook, Twitter, Instagram, YouTube, Pinterest, LinkedIn, WhatsApp etc. are the platforms through which news sharing takes place. 
With the increasing usage of social media sites, Information transfer has not only become very easy, but also very fast and can reach to every corner of the world, leading to fast and easy spread of news, including fake news. The speed at which the news is circulated, and the extent of its impact puts it in a varied category as compared to the traditional media like newspapers.

During the COVID-19, several types of rumours/ fake news/ misinformation has been rapidly spreading across the world. The corona virus pandemic has been spread like fire across the Internet on all social media platforms. In India there are approximately more than 500 to 600 million internet users. During the COVID-19 pandemic lockdown, there was a noteworthy increase or spike in social media platform access and usage. People use the internet for work, entertainment or communication. In the country, Facebook and WhatsApp have seen an upsurge in user activity. Both have approximately more than 200 million users. There has been a steep increase to forwards and incessant information, and misinformation sharing.

There has been a surge in the spread of information during lockdown and also later cause by COVID-19 pandemic. There was a spike in distorted newsfeed shared about different types of cures to the denounced conspiracy about $5 \mathrm{G}$ causing corona viruses. Different types of home-made and herbal cures for COVID-19 infection, a sarcastic humour mocking the government notifications, content related to communalism, clips declaring national emergency were few real time examples of how fake news and misinformation was circulated on the social media platforms. It leads to a widespread alarm and anxiety in peoples' mind. It also made it difficult for the government officials and other support staff and organizations to do their jobs in such difficult times.

There is no practical link between the novel $5 \mathrm{G}$ and the corona virus. But there were $5 \mathrm{G}$ conspiracies from the inception of corona virus. From the start of the corona virus problem, there were almost 50 cases of abuse that led to assault on the telecom engineers. This was believed to be due to the misnomer that $5 \mathrm{G}$ is risky and unsafe. There were also reports of attacks on the infrastructure. Especially in UK, approximately 20 mobile masts were torched. The irony was that the technology used there was $4 \mathrm{G}$ and not $5 \mathrm{G}$.The systems that were powered with this were all support systems to the public like police, fire brigade and hospitals.

During COIVD 19 pandemic, social media companies were facing an array of untrue claims. There were different types of news all over social media like news that the corona virus has been created as a bioweapon, to increase the sale of vaccines, or that Corona is cured by eating garlic or drinking a concoction of bleach concoction. These types of news spread like wild fire. These ideas could be easily disseminated from one person to another through a vast virtual world through different social media platforms.

This led to companies, including Google, Facebook and Twitter to working on combating this coronavirus misinformation. They worked in collaboration with the 'World Health Organisation' to help eradicate misinformation about coronavirus. This has helped big tech companies, to fight against rumours and false information about COVID pandemic on the internet.

\subsection{What is false news?}

Modern false news is different from the earlier overstating or false broadcasting. It has three parts: the who, the what, and the how.

Who

Who are the people who are spreading the fake news, whether they have political agendas, like spy agents, or are they tech savvy individuals looking for making quick money.

What

This includes knowing the source of news. What was the original information, and how it is tweaked to spread false information?

\section{How}

How the misinformation is spread. There are different aspects of delivering news via different social media platforms. The news is delivered in such a way that people are more likely to believe in the false news.

Social media gathers and distributes stories from different sources, irrespective of the accuracy, authenticity or any political leanings of the origin of the story. 
Secondly, news stories are forwarded to individuals via their friends, family of contacts they follow. This endorsed the story. These unspoken recommendations/ endorsements make people accept the messages or stories they get. Messages are often shared in groups, and there is no indication of their origin when they are forwarded.

There are utilities in some Social media platforms which automatically tag articles which get more number of views or likes. These like or views are indications of their popularity. Based on the high count of views and likes people tune in to a story.

\section{Objectives of the Study}

- To understand spreading of fake news through social media

- To understand actions taken by different social media giants to reduce or stop the spread of fake news

\section{Literature Review}

In an experiment by Zhao et. al two social sites were compared for the propagation of news whether the shared news is real news or not real. They found that the fake news spreads uniquely from the real news in its nascent stage itself. Most studies emphasis on theoretical modelling based on machine learning. The study also states that we cannot ignore theoretical models and methods like Black-box method.

Meel, P et.al. discusses the importance of the social media. It discusses how it can impact the public perceptions about an entity like organization, person. It states that if this news is not vetted how it be dangerous to various entities in focus. The article gives taxonomy and classifies the news, identifies various stages of the news. It also methods to make such news reliable.

Jahng et. al. (2020) in this article, the authors made a study on the practitioners. It was related to their understanding the fake news and methods to verify the news. They felt fake news was one of the major factors that affected their quality of news. It was suggested by them that it would be better to have the official source of information to vet the news.

Silva et. al. (2020) in his article focusses towards automatically filtering fake news in Portuguese. Expert Systems with Applications, 146, 113199. In the article, the authors make a point that there is no such method of classification and detection of fake news. The article discusses how machine learning methods are used for detection of fake news. Various case scenarios were conducted with their conclusions. The main goal was classification. In the study 'Machine learning' algorithms were used to detect fake news.

Yavary et. al. (2020) in this article, the authors discuss possible method to verify any news on social media. One is with authentic news agencies and the other is where the sites have a user feedback. It propagates of classifying the information from these sources as "verified" and the unverified news as further as true and false.

The paper defines, classifies the fake news generated on social media. It tries to interpret the damage that it is creating. It also provides taxonomy, one of the first of its kind. The taxonomy is as per the classification of malicious information content that is created at various stages. It also discusses the established technologies to handle these problems. The target is to understand the origin, spread, discovery and control stages.

The paper discusses the array of activities that social media affects. It discusses use cases of fake news propagation and its long run impact. It talks about algorithms used in verifying news generated on social media. It talks of macroscopic and microscopic approaches in addressing this issue. It discusses the Daley-Kendall (DK) model in this context. And the study conducted in verifying the content using DK model Piqueira, J. R.et. al. (2020).

Kaliyar, R. K. et. al. (2020) in this article, an extensive research was carried on AI algorithms used for fake news detection. Earlier the major area of thrust was classification, reviews of the online data. But here neural networks were proposed for detection of fake news. This research sheds light on understanding neural networks and its usage in fake news detection.

TS, S. M., \& Sreeja, P. S. (2020) in this article, the major problems occurring due to fake news are discussed. A review of existing research papers on identification and detection of fake news has been conducted. 


\section{Methodology}

Social media platforms Facebook, Twitter and WhatsApp have been taken into consideration for study.

Secondary data was collected by perusing different report and transcriptions for a 'sense of whole', relevant units were identified and clustered in order to identify emergent themes and draw inferences and conclusions. In the conduct of this study, external data made available by entities such as Government, Trade associations, user groups, consumer federations, service providers, libraries, books, newspapers, journals, databases and the Internet were perused. Significant scrutiny of qualitative data has also been conducted as part of the secondary data to gain a holistic overview of the context under study with reference to its logic, arrangements, explicit and implicit rules.

\section{Discussion}

\subsection{Types of Misinformation}

In the spread of misinformation, there are seven types of misinformation which have been identified. They are "False Connection", "Misleading Content", "False Context", "Imposter Content", "Manipulated Content", "Fabricated Content" and "Satire or Parody".. All the seven types can be propagated by technological cognitive thinking of general mass and are many a times mainly for political propaganda.

Table 1. Types of Information

\begin{tabular}{|c|c|c|c|c|c|c|}
\hline $\begin{array}{l}\text { False } \\
\text { Connection }\end{array}$ & $\begin{array}{l}\text { Misleading } \\
\text { Content }\end{array}$ & $\begin{array}{l}\text { False } \\
\text { Context }\end{array}$ & $\begin{array}{l}\text { Imposter } \\
\text { Content }\end{array}$ & $\begin{array}{l}\text { Manipulated } \\
\text { Content }\end{array}$ & $\begin{array}{l}\text { Fabricated } \\
\text { Content }\end{array}$ & $\begin{array}{ll}\text { Satire } & \text { or } \\
\text { Parody } & \end{array}$ \\
\hline $\begin{array}{l}\text { Content and } \\
\text { titles or } \\
\text { headlines } \\
\text { don't match } \\
\text { up }\end{array}$ & $\begin{array}{l}\text { When Content } \\
\text { is or changed } \\
\text { to mislead } \\
\text { either a person } \\
\text { or event }\end{array}$ & $\begin{array}{l}\text { When good } \\
\text { content is } \\
\text { shared with } \\
\text { wrong or } \\
\text { irrelevant } \\
\text { context }\end{array}$ & $\begin{array}{l}\text { When } \\
\text { known } \\
\text { sources are } \\
\text { copied or } \\
\text { mimicked }\end{array}$ & $\begin{array}{l}\text { When } \\
\text { Content is } \\
\text { modified to } \\
\text { trick } \\
\text { someone }\end{array}$ & $\begin{array}{l}\text { Complete } \\
\text { modified } \\
\text { content to } \\
\text { trick or do } \\
\text { harm }\end{array}$ & $\begin{array}{l}\text { Content } \\
\text { changed } \\
\text { but only } \\
\text { dupes, not } \\
\text { harmful }\end{array}$ \\
\hline
\end{tabular}

Table 1 depicts the seven types of Mis and Disinformation with a brief description on each type. The problem of information quality in the Internet has led to the development of certain phenomena. These include: Content bubbles, Unintentional falses /opinions ("misinformation"), Intentional false or amplifiers ("Disinformation") and Disinformation (or influence) operations.

- Amplifiers/Intentional Falses (Disinformation): In this example, there is a clear intention to manipulate public opinion. Some of these information are recognized via the loads as faux, others are circulated at a fee, which affects the opinion of the public by creating confusion for customers.

- Disinformation/Influence operations: It is a variation of intentional disinformation but takes place at a far large scale and refers to politically or commercially encouraged manipulation strategies. Examples encompass country-backed interference in country wide elections and site of strategically crafted messages on premium advertising structures to discredit industrial opponents.

- Opinions/Unintentional Falses (Misinformation): Expression of opinion, regardless of the extent of veracity, can cause the manipulation of public opinion even though there is no purpose to do so. The Internet permits for the huge scale propagation of such information item, a number of which may be real and some of which may be false.

- Content Bubbles: The Content Bubble phenomenon is found whenever an character interacts with any precise news item. These information items are exhibited to the consumer based on their likes and dislikes. The algorithm which makes a decision the news item to be exhibited to the consumer can be prompted with the aid of behavioural biases (for e.g. Confirmation bias wherein customers have a tendency to like what they already believe) and customized seek, drawing from the hunt history of customers and making to be had content sourced from a narrow subset of statistics.

\subsection{How to spot False news}


Table 2. How to check for false news

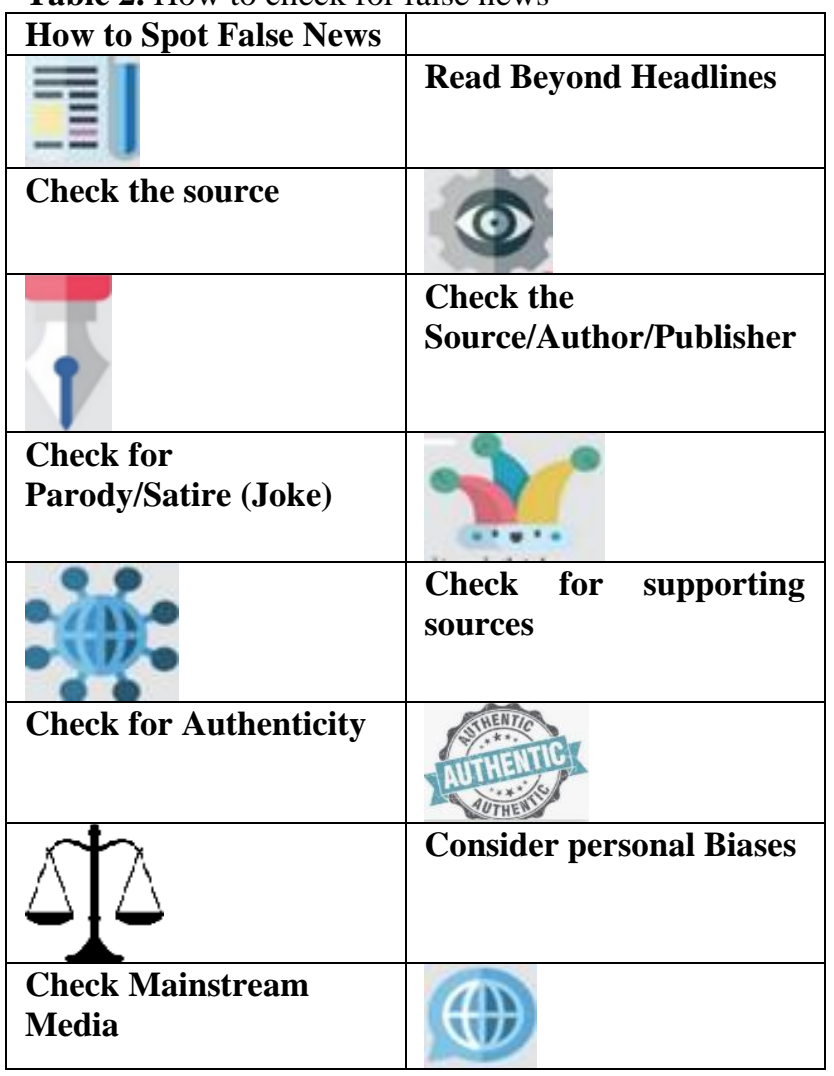

The fundamental measures to counter false news are to promote media literacy. Establishing constructive dialogue with online platforms will help mobilise and coordinate the fact-checkers. The approach of regulation (first self-regulation, then co-regulation if needed) will be highly beneficial. Definition of indicators and sharing of practices must be undertaken to accurately monitor self-regulation and to stimulate innovation."

Efforts in combating false news must take into account mutually legislative and non-legislative methods as each has its own peculiarities. First, the measures must take into account how technology enables the propagation of false news and how the general public are inclined to believe it. Second, the falsehoods being spread on social media need to be clearly distinguished. Third, efforts should be complimentary to ongoing initiatives at building up national consensus and social resilience. Fourth, counter-narratives challenging false news must be circulated expeditiously as technology enables the rapid propagation of false news.

Some nations consider regulation as the handiest methodology to combat the faux information pandemic. The legislative proposals delegate the duty of detecting and preventing the propagation of faux information on generation businesses and people. Social media systems including Facebook and Twitter have already begun deploying gear to hit upon and take down illegal content material and social bots gift at the web sites. The constructing of the faux news detection version as part of this project is an effort inside the equal vein, it could be deployed via social media platforms to locate and take down false information objects, accordingly helping corporations fulfil their regulatory commitments. 
Table 3. False news legislation world wide

\begin{tabular}{|l|l|l|}
\hline \multirow{2}{*}{ COUNTRY } & \multicolumn{2}{|l|}{ LEGISLATION } \\
\cline { 2 - 3 } & STATUS & ACCOUNTABLE PARTY \\
\hline Germany & Approved & Technology companies \\
\hline Italy & Pending & $\begin{array}{l}\text { Individuals, website administrators, Internet Service Providers (ISP), } \\
\text { schools }\end{array}$ \\
\hline The Philippines & Pending & Individuals and technology companies \\
\hline Russia & Pending & Technology companies \\
\hline \multirow{2}{*}{ USA } & Pending & Technology companies \\
\cline { 2 - 4 } & Pending & Technology companies \\
\hline UK & Pending & Technology companies \\
\hline Australia & In progress & $\begin{array}{l}\text { Technology companies, online advertisers and other parties who benefit } \\
\text { from disinformation. }\end{array}$ \\
\hline Israel & Pending & Technology companies \\
\hline India & Approved & Administrators of social media groups \\
\hline Canada & In action & Mass media \\
\hline
\end{tabular}

(source:https://www.rsis.edu.sg/wp-content/uploads/2018/03/PR180307_Countering-Fake-News.pdf)

Technological design could be leveraged to sell content which has accelerated credibility and/or to provide the content material in a way which fosters vital evaluation and patron scepticism. Algorithms can be deployed to become aware of bogus information fabric, for e.g., the articles compiled for economic gain by means of Macedonian teenagers. They may also be deployed to flag questionable information gadgets. Digital content material distributors have to also be aware that each one decisions contain a trade-off: making particular content material extra easily accessible reduces the chance of customers encountering contradictory facts and also consequences within the segregation of users. For example, Google's "container" will be criticised at the floor that almost no person explores the search results while Google solutions a query in a highlighted field.

There need to be some approach of identifying and explicitly labelling bots in conjunction with certain different restrictions imposed on their use in conjunction with different methods of boosting the perceived popularity of a specific item of content. For instance, bots could be required to use CAPTCHA to restrict bots from sharing news objects. Platforms could also introduce a mandate requiring all users to open a link before sharing or retweeting it to growth the chance that the user reviewed the content she or he became selling. Content intermediaries ought to boom their transparency stages via disclosing the factors based totally on which certain information items are promoted over the others. Search engines may also contemplate adopting features that better correlate with accuracy, trustworthiness and high-quality than the quantity of hyperlinks or range of clicks.

Table 3 depicts that majority of the respondents of a survey carried out with the aid of researchers of the "Truth Behind False News" file consider that news corporations and social media groups need to take on the onus of detecting and preventing faux information, consistent with the findings of our project. The building of the faux information detection model is thus established.

Cybercriminals adapt, hustle, diversify and are locating greater like states in spite of being high-profile regulation enforcement strategies towards crook groups and groups in 2018, the opportunity of danger organizations to continue operational importance the considerable upward thrust within the maturity and resilience of crook networks in 2019. Our analysis suggests old traditional cybercrime and financially stimulated in addition to targeted actions, assault will continue to come to be an enormous chance for person Internet users in addition to groups. But criminal operations will by and large preserve to transfer their procedures to put off the dangers of detection as well as disruptions. They may also try and boom and maximize the return on effort in masses ways such as:

1.Moving away from collaborations to working within close-knit syndicates

2. Taking a gain of familiarity with the neighbourhood surroundings and organizations

3.Increasing the accuracy of focused on via using valid files to perceive probable victims before turning in malware 
4. Selling and buying direct get admission to networks for ransomware transport instead of carrying out advanced intrusions.

Different type of news and partisan bias are prevalent on different news media. Hybrid motives create new dangers in ransomware defense and reaction The ransomware hazard may be decreased similarly through the distribution of get admission to employer networks - thru which an attacker can put ransomware on a organization-huge scale - and the capacity of ransomware with self-propagating capabilities (WannaCry) to remerge may also need to create a huge hazard to businesses, especially those with time-crucial operations. While the actual intention behind such an assault can also additionally appear to be to be monetary, proposed ransomware assaults can also moreover at instances supply hybrid sports, anywhere economic, ideological, or political. No count number motive, whether the ransomware threat maintains, companies are inclined to ensure that they take required precautions to prepare, save you, come across, respond, and prevent a corporationmassive ransomware attack. With the possibility that an reputedly financially-stimulated ransomware attack may additionally in fact serve different purposes, a ransom price won't assure the restoration of organisation information; so companies need to plan for the recovery of operations, even in the event of a disruptive lack of records.

\section{Among teens, deleting or restricting their social media posts is relatively uncommon}

\% of U.S. teens who say they ever do the following on social media

\begin{tabular}{|c|c|c|c|c|}
\hline & - Often & = Sometimes & - Rarely & - Never \\
\hline $\begin{array}{l}\text { Organize their feed to } \\
\text { only see certain content }\end{array}$ & 15 & 31 & 22 & 29 \\
\hline $\begin{array}{r}\text { Delete/restrict access to } \\
\text { their posts because it } \\
\text { could negatively impact } \\
\text { them later }\end{array}$ & 9 & 23 & & 37 \\
\hline $\begin{array}{l}\text { Delete/restrict posts } \\
\text { because they don't want } \\
\text { their parents to see }\end{array}$ & 9 & 20 & & 42 \\
\hline
\end{tabular}

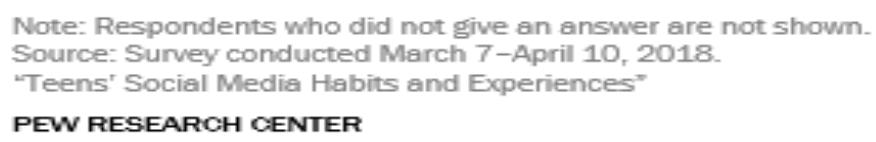

Figure 11. Uncommon Factors

Figure 1 depicts the lack of precautions taken by teenagers surveyed by the Pew Research Center to prevent the display of false news on their social media feed. Better surroundings hygiene is enhancing threats to the deliver chain, turning buddies into frenemies The worldwide interconnectedness of enterprise, the bigger adoption of traditional employer cyber threat countermeasures and improvements to essential cybersecurity hygiene seem like pushing cyber threat actors to are seeking new avenues to compromise businesses, including targeting their supply chains - which includes those for software program application, hardware and the cloud. Organizations ought to mechanically searching for entire attention in their risk standards' and points of supply chain threats. Organizations ought to attempt to suggest regions that protect toward the cybersecurity risks inherent within the panorama of modern-day-day global commercial company strategies through taking part cyber threat intelligence into M\&As and different focussed essential movements, adopting supplier and production unit trying out into their strategies, and enforcing enterprise focused regulations and risk adulthood standards.

\subsection{Action Taken by Different Social Media Platforms During the COVID-19 Pandemic}

\subsubsection{Facebook}

Facebook has been working on its "Remove, Reduce, Inform" process which was first announced in 2016.

Facebook has been working on its "Remove, Reduce, Inform" procedure which was launched in early 2016. Following are the steps taken in order to achieve this $3 \mathrm{R}$ in their process. 
Eliminating the so called Dangerous information: [REMOVE] : There are some standards constituted by Facebook as Community Standards.so whatever information gets posted which sets the red flags to these standards is automatically prevented to move forward and get posted. But in spite of this, some information may still slide from this check-point. The goal is to find such information and remove it as fast as possible. The test here is that it happens mostly in closed groups.95\% of such issues are addressed. It has introduced a "Recent Updates" tab in its Community Standard. This monitors the recent posts in a given timeline like last 2-3 months. Facebook has also introduced a tool termed "Group Quality". This tool gives an overview of deleted or flagged information which was controversial.

Reducing or limiting the distorting information: [REDUCE] It is practically very difficult to differentiate in the harmful, misleading and useful, sound information. This is important due to the fast and uncontrolled spread of information. Facebook is strategizing to collaborate with the select academicians, journalists, experts, civil servants any other experts to fast check on the information spreading through the networks who can vet the information. This exercise can promote true information.

FB is also strategizing to expand its fact-checking process by third party support: [INFORM]

The first important step is to restrict those groups who share and circulate the fake or misinformation: FB has a policy of flagging those groups which circulate false information or support this. They do not get the membersnews details. The admins get incentives for fact-checking their own information. It also restricts the members to get new posts.

New tools launched: There are a few tools launched like the "Click Gap". It's a graphical kind of tool which helps to monitor the quality of the posts. The low quality posts can then be identified and decision taken related to it. The other tool is "Context Button". It gives the people details like articles, their author publishers so that they can decide if they wish to read and share it.

SOP of FB's false news identification and feedback:

- FB attempts to identify fake or false news by analysing the feedback from the users of Facebook. There are also people who do the task of verification of the news and facts. They also identify stories to review on their own. These people are also called as 'Fact-Checkers'.

- If these so called 'Fact-checkers' go and rank any appearing news as false or fake, its overall ranking also reduces. Due to which the total number of people who see it gets lessened and its reach is hampered.

- Pages and websites that repeatedly share false news will see their distribution reduced and their ability to advertise removed.

- Face book has built in an algorithm of raising an alert if a 'fake news' designated by the fact-checkers is shared with other users. The authors, the other users as in the readers and also the admins receive a notification stating that the news was verified as fake.

- Identification of false news through community and third-party fact-checking organizations. It helps to restrict the spread of false news.

- Though monetization is win-win call for both, FB and the clients, Ad purchasing for people in spreading fake news was banned with the of strict enforcement of policies.

- Applying new algorithms and AI based machine learning to assist the response teams in detecting fraud and enforcing policies against inauthentic spam accounts.

- Updating detection of fake accounts on Facebook.

"Educating the public": It is understood that, in general all users have a reactive response to all newsfeeds. It is in the best interest of all users to understand that, such a response is not really worthy. Instead as a standard measure, they can decide the credibility of any newsfeed before believing it. If this is done it will be very easy to control the impact of false information. Users of Facebook can post whatever they want, and people are inclined to believe any headline or read any statistics. FB provides more information to the community to learn more through short films which are available on the FB page in Helping tools.

Facebook also provides guidelines to people to be aware and to understand misinformation/ fake news:

- "To be skeptical of headlines": It has been found that false newsfeeds often have appealing headline. These headlines are displayed $n$ 'all caps' format with exclamation points. They may have some shocking claims which are unbelievable.

- "Look closely at the link": Embedded links which are phony or look-alike of existing ones are a lead to false news. These sites are a copy of the original with tiny changes. Users need to visit the original sites in order to compare results. 
- "Investigate the source": Users need to validate before reacting and believing any newsfeeds. This can be done by checking the source/ author.

- "Watch for unusual formatting": Untrustworthy links, web-sites may contain weird or awkward kind of designs. They may also have grammatical errors.

- "Consider the photos": The questionable newsfeed may also consist of images, videos which have been tampered or changed. The photos used may be authentic, but may be not relevant to rest of the information. The users need to look for the source.

- "Inspect the dates": False newsfeed may display erroneous timelines i.e. which are haphazard, irrelevant and make very less meaning or the calendar-dates may be changed.

- "Check the evidence": Users need to check the source of newsfeed or to verify that they are accurate. Unnamed experts or lack of source may suggest false news.

- "Look at other reports": If other news sources do not report the same newsfeed, it may be taken as a clue that it is false. If the news feed gets reflected by many sources users can trust it.

- Sometimes false news comes in the form of humour and satire. These may be difficult to trace as false. Here, the users can check if the source is famous for parody, and if the information and tone suggested is just for fun. Users have to think critically about the feeds one reads, and only share those that one knows to be credible.

During the pandemic there was widespread of rumours across several social media platforms. Facebook has been fighting the spread of false news in different areas special in the following key areas:

- Most of the false news is motivated financially, hence Facebook took steps in disrupting economic incentives;

- Several new products were introduced to stop the spread of news which was not true;

- Through the platform, Facebook motivated and helped people to tackle false news by taking informed decisions.

-

\subsubsection{WhatsApp}

Mobile phones are the largely owned gadget in this century by individuals. Due to which the usage of WhatsApp is also highest. Miscreants use this social media for generating and spreading fake news as it is easy to do here. WhatsApp has addressed this fake news issue for a long time.

WhatsApp has an built-in facility to reduce the fake news propagation by applying a limit to the number of times a message is being forwarded. It has also launched many notations, representations for representing them.

If a message is forwarded at least five times, it is called as a "frequently forwarded" message. A new double arrow indicates to the users that the message is a frequently forwarded message, and the user is aware that the said message is not forwarded by one of their close contact. This helps users to identify information or fake news. The messages that are identified as "frequently forwarded" can be forwarded only one at a time.

In the wake of Covid-19, there was a huge spike in the fake news generated related to Covid-19. This triggered the launching of a special tool i.e." Chabot". It was in partnership with the health ministry for circulating authentic information on covid-19, preventive measures to be taken for Covid-19, the misinformation, and avoiding the fake news in India.

In UK, the team of the UK government and the WhatsApp personnel have launched the novel Chabot. This is automated and answers any queries or doubts related to health. This bot is also enabled to minimize the propagation of the fake news. The Machine learning applications form a part of the algorithms to combat the users involved in mass messaging the fake news.

\subsubsection{Twitter}

Twitter historically described a "free speech wing of the free speech party", and in the early days it definitely had no protocol or policies to prevent and avoid the spread of any false information. It had not introduced any policies for preventing any misinformation.

Twitter does not have any option of user flagging. If any user sees information on twitter which is not in coalition with the global and local public health information, then the Users can report misinformation. The same will then be assesses by Twitter, and appropriate action will be taken. 
In the Covid-19 times, Twitter was motivated on providing accurate information related to Covid-19. It partnered with the health authorities in order to guide the users to the correct sources whenever they explore for covid related information.

When COVID-19 was declared as pandemic, it added rules to stop attempts of Twitter usage by advertisers to target any inappropriate advertisements related to Covid-19. Or any opportunistic usage of the Covid-19 by the advertisers. Twitter also started banning tweets that promote any misleading claims or assertions about coronavirus. Along with banning it also has begun to eliminating tweets that could be spread and turn out dangerous and harmful by their misinformation about Covid-19.

\subsection{Use of Technology and algorithms in identifying Fake News}

In the current times, technology plays a crucial role in identification and detection of fake news. Most social media are turning to use this methodology to curb the fake news. The basic concepts used are data mining techniques with algorithms like feature selection, Natural language processing, Document-term-matrix construction.

Similarly, the concept of artificial intelligence is also used. Almost 23 algorithms are used for the classification of news. There have been studies carried out on fake news using these 23 algorithms. These are: "BayesNet", "JRip", "OneR", "Decision Stump", "ZeroR", "Stochastic Gradient Descent (SGD)", "CV Parameter Selection (CVPS)", "Randomizable Filtered Classifier (RFC)", "Logistic Model Tree (LMT)"," Locally Weighted Learning (LWL)", "Classification Via Clustering (CvC)", "Weighted Instances Handler Wrapper (WIHW)", "Ridor", "Multi-Layer Perceptron (MLP)", "Ordinal Learning Model (OLM)", "Simple Cart", "Attribute Selected Classifier (ASC)", "J48", "Sequential Minimal Optimization (SMO)", "Bagging,Decision Tree", "IBk", and "Kernel Logistic Regression (KLR)".

The major logic used is classification and clustering of the news items. With the help of classification, the fake news can be cornered and filtered out.

\subsection{Steps Taken by Countries for Curbing misinformation/ Fake News INDIA}

Different types of Apps have been introduced through different social media platforms. The MyGov Corona Helpdesk App is announced by WhatsApp by partnering with the Government of India. In different states of India, similar services have been introduced so that users can find credible and accurate information in in English as well as different regional languages specific to their region like Marathi in Maharashtra, Kannada in Karnataka etc..,.

In India there is no "fake news" Law. In response to Covid-19, and the surge of fake and false news related to Covid, the State government invoked the "provisions of Epidemic Diseases Act, 1897" and "Disaster Management Act 2005" to control this menace.

Based on these provisions nearly 100 people have been arrested in India on charges related to spreading misinformation about the coronavirus.

The Indian state of Maharashtra, has passed also specific orders which mandate approval from the government for disseminating any information related to the corona virus.

\section{European Countries}

Steps have been taken by different countries to stop the spreading of misinformation/ fake news from early times. In 2018, a 'high-level group of experts' ( HLEG) was set up to advise on creating polices to counter fake news and disinformation spread online by the European Commission.

The HLEG advised the Commission against simplistic solutions. Recommendations of HLE Gare based on a various interconnected and responses which are mutually reinforcing.

These responses are designed to:

1. "Enhance transparency of online news";

2. "Promote media and information literacy";

3. "Develop tools for empowering users and journalists to tackle disinformation"; 
4. "Safeguard the diversity and sustainability of the European news media ecosystem", and

5. "Promote continued research to evaluate the measures taken by different actors and constantly adjust the necessary responses."

During the COVID pandemic, the United Kingdom National Health Service has taken different steps to remove the Twitter accounts that were spreading information which was not true or misleading. (https://www.nytimes.com/2020/03/08/technology/coronavirus-misinformation-social-media.html)

It was decided to remove lot of content which was earlier allowed in Twitters rules. Some of these include:

- "Denial of health authority recommendations"- "with the intent to influence people into acting against recommended guidance".

- Some treatments were posted which weren't found to be to have immediate harmful impact. Some of them were - "coronavirus is not heat-resistant" - "walking outside is enough to disinfect you" or "use aromatherapy and essential oils to prevent Covid-19."

- Various Posts of treatments especially for Covid-19.

- Definite and unconfirmed posts that provoke the common-people to react, creating a panic or alarming situation, such as: "The National Guard just announced that no more shipments of food will be arriving for 2 months - run to the grocery store ASAP and buy everything!"

- $\quad$ Prorogation of fake, false and misleading posts like for example "how to differentiate between Covid19 and a different disease"

\section{Conclusion}

The year 2020 is going to be historical in many ways, it's the year of the pandemic. The struggle faced to face and control the pandemic. During this crisis, various countries implied the lockdown. During these periods, there was a great commotion on the social media. Due to surge in fake news concerned with Covid-19, governments had to put regulations on the use of social media related to Covid-19. From the study the authors find that there is no standard set of protocols of addressing the fake new. All social media are having their own way of handling this issue. Most times, checking the source and authors was considered best to check the fake news. Special software applications were developed for tracing the Covid-19 discussions and barring the fake news from getting propagated. This was because this fake news did more harm psychologically to people. The software applications are now a trend-setter in digital health-informatics. This may be the need of this era and may be widely in use hence on. The technology has now come to play a part as new algorithms are being developed, tried and tested.

\section{References}

1. Amnesty International. (2017 March 24). Amnesty International. "Mexico: "Open Season" on Journalists as Third Reporter Killedin a Month." Last accessed on 31 May 2017, https://www.amnesty.org/en/press-releases/2017/03/mexico-open-season-onjournalists-as-thirdreporter-killed-in-a-month/.

2. Andy Swan. (2017 May 21). Forbes. "Secrets of Smart Investors Profiting from Market-Moving Tweets." Last accessed on https://www.forbes.com/sites/andyswan/2017/05/21/secrets-of-smart-investors-profiting-frommarket-movingtweets/.

3. BBC Trending. (2017 May 9). BBC. "Macron Leaks: the anatomy of a hack." Last accessed on 31 May 2017, http://www.bbc.com/news/blogs-trending-39845105.

4. Ben Collins. (2017 May 23). The Daily Beast. "Manchester Death Hoax Makes It All the Way to Fox News." Last accessed http://www.thedailybeast.com/articles/2017/05/23/trolls-made-it-all-the-way-to-fox-news-withtheir-manchesterdeath-hoax.

5. Ben Popken. (2017 April 11). NBC News. "SEC Cracks Down on Fake Stock News." Last accessed on 23 May 2017, http://www.nbcnews.com/business/markets/sec-cracks-down-fakestock-news-n745141.

6. Brian Dillon. (2006 September 1). Tate Online. "The revelation of erasure." Last accessed on 31 May 2017, http://www.tate.org.uk/context-comment/articles/revelation-erasure.

7. Chanson d'automne (@Rogue_Eyre) “@@Twitter PLS STOP TROLLS posting fake \#Manchester victim pics.” $23^{-}$May 2017, 11:01 AM. Tweet. https://twitter.com/Rogue_Eyre/status/866851441729830912. 
8. Craig Silverman. (2016 November 17). Buzzfeed News. "This Analysis Shows How Viral Fake Election News StoriesOutperformed Real News On Facebook." Last accessed on 30 May 2017, https://www.buzzfeed.com/craigsilverman/viralfake-election-news-outperformed-real-news-onfacebook.

9. Craig Silverman. (2016 November 17). Buzzfeed News. "This Analysis Shows How Viral Fake Election News Stories Outperformed Real News On Facebook." Last accessed on 30 May 2017, https://www.buzzfeed.com/craigsilverman/viralfake-election-news-outperformed-real-news-onfacebook.

10. Danny Westneat. (2017 March 29). The Seattle Times. "UW professor: The information war is real, and we're losing it." Last accessed on 30 May 2017, http://www.seattletimes.com/seattlenews/politics/uw-professor-the-information-war-is-real-andwere-losing-it/.

11. David Schrieberg. (2017 January 9). Forbes. "Fake News Threatens Critical European Elections." Last accessed on 23 May2017, https://www.forbes.com/sites/davidschrieberg1/2017/01/09/fakenews-threatens-critical-european-elections/.

12. Feike Hacquebord. (2017 January 12). Trend Micro. How Cyber Propaganda Influenced Politics in 2016. Last accessed on 31May 2017, http://blog.trendmicro.com/trendlabs-securityintelligence/cyber-propaganda-influenced-politics-2016/.

13. George Cybenko, Anarita Giani, and Paul Thompson. (2003 October 6). Cognitive Hacking. Dartmouth College. Last accessedon 31 May 2017, http://www.ists.dartmouth.edu/library/301.pdf

14. GMP Oldham (@GMPOldham). "Police have attended an incident@ 0 roh Scene searched, no offences and all staff \&patient'sare safe \&well" 23 May 2017, 8:43 AM. Tweet. https://twitter.com/GMPOldham/status/866816891968299009

15. Hamburger, Y., \& Vinitzky, G. (2010). Social network use and personality. Computers in Human Behavior, 26(6), 1289-1295.

16. J. Soll, "The Long and Brutal History of Fake News," POLITICO Magazine, 18-Dec-2016. [Online]. Available: http://politi.co/2FaV5W9. [Accessed: 02-Aug-2018].

17. Jack Wagner (@jackdwagner). “teens are making up fake 'missing' friends at the ariana grande concert to get RT's. this is sodystopian.” 23 May 2017, 9:39 AM. Tweet. https://twitter.com/jackdwagner/status/866830963178786817.

18. Jahng, M. R., Lee, H., \& Rochadiat, A. (2020). Public relations practitioners' management of fake news: Exploring key elements and acts of information authentication. Public Relations Review, 101907.

19. John Bacon. (2017 April 13). USA Today. "United Airlines passenger dragged off flight suffered concussion, broken nose." Last accessed on 30 May 2017, https://www.usatoday.com/story/news/nation/2017/04/13/united-airlines-david-dao-familypressconference/100409492/.

20. Jon Ronson (2015 December 20). The Guardian. "How the online hate mob set its sights on me." Last accessed on 31 May2017, https://www.theguardian.com/media/2015/dec/20/social-mediatwitter-online-shame.

21. Journalists on demand, or what kind of article you can buy for 15000 RUB. Last accessed on 23 May 2017, https://life.ru/t/

22. Kaliyar, R. K., Goswami, A., Narang, P., \& Sinha, S. (2020). FNDNet-A deep convolutional neural network for fake news detection. Cognitive Systems Research, 61, 32-44

23. M. Potthast, S. Kopsel, B. Stein, and M. Hagen, "Clickbait Detection," in Advances in Information Retrieval: 38th European Conference on IR Research, ECIR 2016, Switzerland: Springer, 2016, pp. 810-817.

24. M. Wendling, "The (Almost) Complete History of "Fake News," BBC News, 22-Jan-2018. [Online]. Available: https://www.bbc.co.uk/news/blogs-trending-42724320. [Accessed: 02-Aug2018].

25. matter of national security." Last accessed on 30 May 2017, http://www.latimes.com/world/europe/la-fg-ukraine-website-ban20170518-story.html.

26. Matthew Rocco. (2017 May 9). Fox Business. "Spirit's Stock Takes a Hit After Airport Fight." Last accessed on 30 May 2017,http://www.foxbusiness.com/markets/2017/05/09/spirits-stocktakes-hit-after-airport-fight.html.78 | The Fake News Machine: How Propagandists Abuse the Internet and Manipulate the Public

27. Meel, P., \& Vishwakarma, D. K. (2019). Fake news, rumor, information pollution in social media and web: A contemporary survey of state-of-the-arts, challenges and opportunities. Expert Systems with Applications, 112986. 
28. Meel, P., \& Vishwakarma, D. K. (2019). Fake news, rumor, information pollution in social media and web: A contemporary survey of state-of-the-arts, challenges and opportunities. Expert Systems with Applications, 112986.

29. Merriam-Webster, "The Real Story of 'Fake News,"” 23-Mar-2017. [Online]. Available: https://www.merriam-webster.com/words-at-play/the-real-story-of-fake-news. [Accessed: 02-Aug2018].

30. Nielsen, J. S. (2011). Use of the Internet for willingness-to-pay surveys: A comparison of face-toface and web-based interviews. Resource and Energy Economics, 33(1), 119-129

31. O'Connor, C., \& Murphy, M. (2020). Going viral: doctors must tackle fake news in the covid-19 pandemic. bmj, 24(369), m1587.

32. Piqueira, J. R., Zilbovicius, M., \& Batistela, C. M. (2020). Daley-Kendal models in fake-news scenario. Physica A: Statistical Mechanics and its Applications, 548, 123406

33. Sabra Ayres. (2017 May 18). Los Angeles Times. "Ukraine blocks popular Russian-owned social media sites, saying it's a

34. Silva, R. M., Santos, R. L., Almeida, T. A., \& Pardo, T. A. (2020). Towards automatically filtering fake news in Portuguese. Expert Systems with Applications, 146, 113199.

35. Stefan Nicola and Birgit Jensen. (2017 April 5). Bloomberg L.P. "Germany Gets Really Serious About Fake News on Facebook."Last accessed on 26 May 2017, https://www.bloomberg.com/politics/articles/2017-04-05/merkel-cabinet-backs-facebookfines-tostem-fake-news-in-germany.

36. Tanya O'Carroll. (2017 January 24.) Amnesty International. “Mexico's misinformation wars: How organized troll networks attack and harass journalists and activists in Mexico." Last accessed on 31 May 2017, https://medium.com/amnesty-insights/mexico-s-misinformation-warscb748ecb32e9.

37. Timothy Egan. (2016 January 22). The New York Times. "The Eight-Second Attention Span." Last accessed on 31 May 2017,https://www.nytimes.com/2016/01/22/opinion/the-eight-secondattention-span.html.

38. TitanBuilder1TM (@TitanBuilder1) “ManchesterBombing \#PrayForManchester \#ManchersterArena \#Manchester These are just some of the missing people. RT to help find them." 23 May 2017, 8:36 https://twitter.com/TitanBuilder1/status/866815032809488385.

39. TS, S. M., \& Sreeja, P. S. (2020). Fake News Detection on Social Media-A.

40. V. Goel, S. Raj, and P. Ravichandran, "How WhatsApp Leads Mobs to Murder in India," The New York Times, 18-Jul-2018. [Online]. Available: https://www.nytimes.com/interactive/2018/07/18/technology/whatsapp-india.... [Accessed: 06Aug-2018].

41. Victor Reklatis. (2017 April 12). Marketwach. "United's stock falls 1.1\%, wipes out \$255 million off the airline's market cap. "Last accessed on 31 May 2017, http://www.marketwatch.com/story/uniteds-stock-is-set-to-fall-5-and-wipe-1-billion-offtheairlines-market-cap-2017-04-11.

42. Wang Chen et al. 王晨. (2013 February 18). The New York Times. “删帖生意, 一条灰色产业链 . [A business of taking down post, a chain of gray industry]." Last accessed on 25 May 2017, https://cn.nytimes.com/china/20130218/cc18caixin/.

43. Wikipedia (2017 April 9). Human flesh search engine. Last accessed on 31 May 2017, https://en.wikipedia.org/wiki/Human_flesh_search_engine.

44. Yavary, A., Sajedi, H., \& Abadeh, M. S. (2020). Information verification in social networks based on user feedback and news agencies. Social Network Analysis and Mining, 10(1), 2

45. Zhao, Z., Zhao, J., Sano, Y., Levy, O., Takayasu, H., Takayasu, M., ... \& Havlin, S. (2020). Fake news propagates differently from real news even at early stages of spreading. EPJ Data Science, $9(1), 7$.

\section{Web Sites}

46. Scott Monty. (October 2019) The Fake News Machine: How Propagandists Abuse The Internet.

47. Lion Gu, Vladimir Kropotov, and Fyodor Yarochkin (2016 December 19) Historical Overview: Propaganda, Fake News, and Emerging Technology. Forward-Looking Threat Research (FTR). A TrendLabs Research Paper

48. Roy Greenslade (Wed 23 Nov 2016) Here's the truth: 'fake news' is not social media's fault. Web Site: https://www.theguardian.com/media/greenslade/2016/nov/23/heres-the-truth-fake-news-isnot-social-medias-fault 
49. Paul Chadwick (Mon 19 Mar 2018) Why fake news on social media travels faster than the truth. Web Site: https://www.theguardian.com/commentisfree/2018/mar/19/fake-news-social-mediatwitter-mit-journalism

50. Craig Silverman (November 19, 2016). This Is How You Can Stop Fake News From Spreading On Facebook. Web Site: https:/www.buzzfeednews.com/article/craigsilverman/heres-how-toreport-fake-news-on-facebook; https://www.facebook.com/help

51. Ed VaizeyAnna-Sophie Harling(29 January 2021) Time to curb the fake news running riot on social media

52. .Web Site: https://www.standard.co.uk/comment/comment/social-media-fake-news-b917950.html

53. Rory Cellan-Jones (10 April 2020). Tech Tent: Social media fights a fresh flood of fake news. Web Site: https://www.bbc.com/news/technology-52245992

54. The European Commission's science and knowledge service (26/07/2019). The digital transformation of news media and the rise of disinformation and fake news. Website: https://ec.europa.eu/jrc/en/publication/eur-scientific-and-technical-research-reports/digitaltransformation-news-media-and-rise-disinformation-and-fake-news

55. Saumya Tewari (14 Apr 2020). Covid-19: Social media platforms fight fake news under pressure from government. Website: https:/www.livemint.com/industry/media/covid-19-social-mediaplatforms-fight-fake-news-under-pressure-from-government-11586843895979.html

56. Sheera Frenkel, Davey Alba and Raymond Zhong (March 8, 2020) Surge of Virus Misinformation Stumps Facebook and Twitter. Web https://www.nytimes.com/2020/03/08/technology/coronavirus-misinformation-social-media.html

57. European Commission-Strategy Shaping Europe's digital future-Reports and studies (12 March 2018) Final report of the High Level Expert Group on Fake News and Online Disinformation. Web Site : https://ec.europa.eu/digital-single-market/en/news/final-report-high-level-expert-groupfake-news-and-online-disinformation 